\title{
Development of a new Robot and Design of a 4Axes Intervention Program
}

\author{
Desenvolvimento de um novo Robô e Projeto de um Programa de Intervenção 4 eixos \\ Desarrollo de un nuevo Robot y Diseño de un Programa de Intervención 4 eixos
}

Received: 11/232021 | Reviewed: 11/29/2021 | Accept: 11/30/2021| Published: 12/05/2021

\author{
Kyriaki Sarri \\ ORCID: https://orcid.org/0000-0002-3569-7106 \\ University of Macedonia, Greece \\ E-mail: sarrikiki@live.com \\ Eleni Gkiolnta \\ ORCID: https://orcid.org/0000-0003-4531-9667 \\ University of Macedonia, Greece \\ E-mail: egkiolnta@uom.edu.gr \\ Maria Zygopoulou \\ ORCID: https://orcid.org/0000-0002-9302-4065 \\ University of Macedonia, Greece \\ E-mail: Mariazygopoulou@gmail.com \\ Areti-Eirini Filiou \\ ORCID: https://orcid.org/0000-0002-9510-4739 \\ University of Macedonia, Greece \\ E-mail: Oooareti@gmail.com \\ Christine K. Syriopoulou-Delli \\ ORCID: https://orcid.org/0000-0003-1490-8899 \\ University of Macedonia, Greece \\ E-mail: csyriop@uom.edu.gr
}

\begin{abstract}
This is an observational study using descriptive methods and following the guidelines of cross-sectional studies. Taking into account that the children's needs and abilities are continuously changing, the authors proposed robotbased interventions to enhance independent living skills. Social robots as intervention and therapy agents for children with Autism Spectrum Disorders have been around for quite some time and recent technological advances have brought many changes in their potential and therefore, their popularity. In this article the authors present a pandarobot designed for children with ASD describing its physical appearance, giving information about its features and the ways it can be implemented in an intervention program that is structured in four axes. These four axes include activities that aim towards the development of social, communication, and motor skills and also focus on the implementation of relief and relaxation techniques for children with ASD. Essential guidelines and instructions, as well as certain points of attention, are also discussed.
\end{abstract}

Keywords: Autism; ASD; Robot; Intervention; Scenario; Communication; Social skills; Motor skills; Relaxation.

\section{Resumo}

Trata-se de um estudo observacional com métodos descritivos e seguindo as diretrizes dos estudos transversais. Levando em consideração que as necessidades e habilidades das crianças estão mudando continuamente, os autores propuseram intervenções baseadas em robôs para melhorar as habilidades de uma vida independente. Os robôs sociais como agentes de intervenção e terapia para crianças com Transtornos do Espectro do Autismo já existem há bastante tempo e os recentes avanços tecnológicos trouxeram muitas mudanças em seu potencial e, portanto, em sua popularidade. Neste artigo os autores apresentam um panda-robô projetado para crianças com TEA descrevendo sua aparência física, dando informações sobre suas características e as formas como pode ser implementado em um programa de intervenção que está estruturado em quatro eixos. Esses quatro eixos incluem atividades que visam o desenvolvimento das habilidades sociais, de comunicação e motoras e também enfocam a implementação de técnicas de alívio e relaxamento para crianças com TEA. Diretrizes e instruções essenciais, bem como certos pontos de atenção, também são discutidos.

Palavras-chave: Autismo; ASD; Robô; Intervenção; Cenário; Comunicação; Habilidades sociais; Habilidades motoras; Relaxamento.

\section{Resumen}

Este es un estudio observacional que utiliza métodos descriptivos y sigue las pautas de estudios transversales. Teniendo en cuenta que las necesidades y habilidades de los niños cambian continuamente, los autores propusieron intervenciones basadas en robots para mejorar las habilidades para la vida independiente. Los robots sociales como agentes de intervención y terapia para niños con trastornos del espectro autista han existido durante bastante tiempo y 
los avances tecnológicos recientes han traído muchos cambios en su potencial y, por lo tanto, en su popularidad. En este artículo los autores presentan un panda-robot diseñado para niños con TEA describiendo su apariencia física, dando información sobre sus características y las formas en que se puede implementar en un programa de intervención que se estructura en cuatro ejes. Estos cuatro ejes incluyen actividades que apuntan al desarrollo de habilidades sociales, comunicativas y motoras y también se enfocan en la implementación de técnicas de alivio y relajación para niños con TEA. También se discuten las pautas e instrucciones esenciales, así como ciertos puntos de atención.

Palabras clave: Autismo; TEA; Robot; Intervención; Escenario; Comunicación; Habilidades sociales; Habilidades Motoras; Relajación.

\section{Introduction and Robot Design}

Various types of robots have been used in autism therapy. Robots are designed to resemble humans (anthropomorphic), animals, or cartoon-like toys (non-anthropomorphic) or not correspond to any biological species (nonbiomimetic) (Cabibihan et al., 2013). Robots from each category are designed to serve different purposes better, as they all have some positive and some negative points. Research data have shown that non-anthropomorphic robots manage to motivate children with ASD (Cabibihan et al., 2013; Kozima et al., 2009; Stanton et al., 2008). In addition, animal-like (zoomorphic) robots with a simple appearance don't resemble humans the way humanoid robots do, so most children with severe autism traits are less likely to become anxious or frightened during interactions (Kumazaki et al., 2020).

For all the reasons mentioned above, a panda-robot named "Bady" was designed which acts as a simplified agent that can facilitate social interaction, as it helps the children with ASD to focus on the information provided (Peca et al., 2014; Syriopoulou- Delli, Gkiolnta, 2021). The robot is two-toned, white and black. The choice of black and white color for Bady was made to avoid over-stimulation, as bright and vivid colors are likely to magnetize the child's attention (Cabibihan et al., 2013). It is made of smooth plastic and has some parts covered with furry material, in order to correspond to the preferences of every child. The robot has wheels on legs, which allow it to move. Moving objects are easier to grab the attention of children with ASD (Cabibihan et al., 2013). At the same time, it can stand on its front legs and perform various movements in the environment. Furthermore, the robot has illuminated parts, which are designed to attract the attention of the child with ASD (Cabibihan et al., 2013; Syriopoulou- Delli, Gkiolnta, 2021; Syriopoulou- Delli, Sarri,2021; Syriopoulou- Delli, Zyrgopoulou, 2021).

The main part of Bady that is illuminated is its pair of eyes, which can be attractive for children and promote interaction (Robins et al., 2010). This feature can be disabled for children with sensory sensitivity. Furthermore, children with ASD tend to exhibit symptoms of anxiety and sensory overload when interacting with human agents and they can also feel overwhelmed by the complexity of their expressions. This is the main reason why the research team chose to keep the robot's expressions simple and minimal, and not mimic the facial appearance of humans, which is more complicated and elaborate (Kumazaki et al., 2020).

Bady is equipped with two speakers and a camera-based vision system that facilitates light detection and navigation. Also, it has built-in microphones and touch sensors that provide extra abilities, like greater degrees of interactivity. The robot can produce speech, which is essential for verbal interactions, and also can facilitate non-verbal communication through its movement, gestures, and special features (such as its luminescent eyes).

A "Wizard of Oz" (WOz) setting is being implemented to control the robot, which allows its semi-autonomous operation (Landauer 1986; Wilson 1988). This operating method does not let the child know whether the therapist controls the robot or the robot acts autonomously, and therapists can program it beforehand and be in control of the intervention process. Also, WOz provides the therapist with the ability to instantly alter and adapt the robot's actions even when unexpected reactions occur (such as discomfort, aggressiveness, symptoms of anxiety, etc.) (Vanderborght et al., 2012). Users can operate Bady through software that is specifically designed for this purpose and offers many different options, as well as some pre- 
designed interaction scenarios for improving the social skills of children with ASD.

The robot provides the necessary security, that is, it does not have angles or edges that can injure the child and is robust to withstand possible drops or blows in case the child is not attentive or is in meltdown. At the same time, it is designed to have a high degree of autonomy. This means that pressing a button on the remote control results in a series of moves being made. It also has a high degree of adaptability, which indicates its ability to gradually adapt to the evolving needs of the child. This ensures the continuous education and development of the child and prevents stagnation (Cabibihan et al., 2013). In the next sections, the authors are going to discuss the implementation of Bady in a 4-Axes structured intervention, that aims towards the development of (1) the sense of relief and relaxation, (2) communication, (3) social, and (4) motor skills, which constitute some of the main impairments that children with ASD exhibit.

\section{Research Methods}

The current article is an observational study that uses descriptive methods and follows the guidelines of crosssectional studies (Rezigalla, 2020; Omair, 2015). This means that the presented information and design was based on the findings of articles that implemented interventions for children with Autism Spectrum Disorders who had interactions with robotic tools. The sample mainly consisted of children that were a) of school age and b) diagnosed with ASD, which were two variables of interest. It's a descriptive study that used samples from a larger population, without any comparisons being made.

The main research questions were: a) what features and characteristics should an educational robot designed for children with autism possess in order to be effective during intervention, b) how can a robotic agent make children with ASD feel more relaxed and relieved, c) in which activities can children with ASD get involved during robotic interactions to increase their social skills, d) can their communication skills be enhanced after interacting with the robot, and e) how can a robot designed for children with ASD help them enhance their motor skills. The first research question (a) is reviewed in the "Introduction" section and the remaining hypotheses are discussed in four sections, each one covering one of the topics noted above.

\section{Results and Discussion}

\section{First Axis: Relaxation and relief}

\section{Phase 1. Introduction}

In the first phase, our goal is to introduce the robot to the child with ASD and to cultivate calm and confidence (Marinoet al., 2020; Spain et al., 2015; Saadatzi et al., 2018). In this phase, the child is introduced to the robot, which takes the form of spontaneous discovery, with the discreet presence of the teacher, who handles the robot, secretly, discreetly, so that the child is convinced of the robot's autonomy and give substance (Saadatzi et al., 2018; Sartorato et al., 2017). The child interacts with the robot through conversation. The questions require first simple answers and then even descriptions. In case there is a lack of speech in the child, actions are followed to demonstrate answers using a tablet and with a tangible interaction with the robot.

Upon entering the session, the robot says "Hello" to the child. This greeting scenario has been developed to provide emotional interaction (Spain et al., 2015; Saadatzi et al., 2018). The robot, at the same time as greeting the child, shakes their hand accordingly to show that it greets them.

The robot asks the child to tell various information to get to know them, such as their name, their favorite color, their favorite toy, if they like music, if they like children's fairy tales, what they do not like and bothers them, what they do in their free time, if they have friends, how they feel and other information about them in order to start the conversation and to show 
the child that it is interested in getting to know them. While asking questions, in order for the robot to show to the child that it is interested in them and to create an atmosphere of trust and intimacy, it makes movements with its hands (swinging up and down) as a person does while talking. This is done so that the robot comes as close as possible to the child. The robot uses the movements of its hands and body, as research shows that it likes and wins children with autism to notice it and want to interact with it (Sharma et al., 2018).

During the first discussion, the robot uses supportive phrases such as well done, very nice, very good what you say to me, and joy, etc. in order to cultivate an initial level of self-confidence in the child. Consequently, the child with autism will slowly begin to feel good about the robot, begin to trust it, and want to stay with it. In addition, the robot says things about itself such as "my name is...", "my favorite color is blue" etc., so that there is a discussion on both sides and the child feels familiar as if talking to a friend (to a "buddy") (Sprung et al., 2015).

During this phase, depending on the preferences and capabilities of each child, games, songs, and fairy tales are integrated, which help even more in the familiarization with the robot as an entity but also as a tool (Sprung et al., 2015). The first phase will be repeated until the child shows the required familiarity, comfort in interaction, as well as confidence in the robot so that they feel safe. It is completed in case the child shows discomfort and refuses to cooperate.

The goal is to introduce the child to the robot, to cultivate an initial relationship of trust, and through conversation, music, and fairy tales the child feels familiar and calm with the robot.

\section{Phase 2. Relaxation}

In this phase, the child receives relaxation training from the robot, which includes 3 steps. These steps were based on the principles and protocol for stress and relaxation techniques offered by Cognitive and Behavioral Psychotherapy (Sharma et al., 2018; Sprung et al., 2015; Wood et al., 2020; Yun et al., 2017). This approach shows that it helps children with autism to relax, feel their body, and be left to the instructions of the announcer, in this case, the robot.

Relaxation training is commonly used to reduce stress and normal arousal. This technique includes diaphragmatic breathing, which can be taught to the patient, muscle tension release activities, and image-based strategies (Storch et al., 2015. Welch \& Graham, 2018). Relaxation can help children and adolescents realize the increased tension, which serves as a sign of relaxation, and they are taught specific relaxation exercises that they can use to reduce tension (Storch et al., 2015).

The first step is to play with the 10 candles, the second is diaphragmatic breathing and the third is progressive muscle relaxation. During relaxation, the robot will play relaxing music while speaking in a slow and quiet voice. In addition, the robot will support the child with phrases such as you are doing very well, well done, continue like this, in order for the child to feel confident and to continue the process of relaxation.

\section{0 candles}

Wexler (1991) created a Ten Candles exercise. The robot tells the child to imagine 10 lighted candles in a row and then extinguish each candle in an attempt to exhale. The robot applies the exercise itself by extinguishing the supposed candle so that we can achieve the imitation of the exercise by the child (Filiou, 2021). This particular intervention combines images and controlled breathing. This can also act as a kind of game between the robot and the child, which aims to start the session and introduce the child to the relaxation that will follow (Storch et al., 2015).

\section{Diaphragmatic Breathing}

In this step, the child learns a breathing technique based on their diaphragm. This focused breathing helps a lot in relaxing and eliminating negative emotions. Inhalation alerts our body, while exhalation has a calming effect (Storch et al., 2015). By focusing on breathing and diaphragm movement, the nervous system can be affected and heart rate can be slowed. 
The robot, therefore, gives verbal instructions to the child on how to perform the breathing. E.g. - Put one hand on the chest and the other on the stomach. - Take air from your nose and let your stomach swell. - Gently and calmly, take the air out of your nose. The robot, while saying the instructions for diaphragmatic breathing, at the same time follows them, putting one hand on the chest and the other on the abdomen. This will make it easier for the child to imitate the robot and do diaphragmatic breathing. At the same time, relaxing music is heard and the robot's voice is in low and soft tones. In addition, the robot strengthens the child with verbal rewards, well done, you are doing very well, he continues, in order to encourage the child to continue the process. 3 and 4 breaths can be taken.

\section{Progressive muscle relaxation}

In this step, the robot instructs the child again with a slow tone of voice and with music in the background, how to gradually relax the muscles of their body. It starts from the bottom up. First the toes, the whole foot, the waist, the back, the fingers, the whole hand, the neck, and finally the head. The robot gives instructions to the child such as: - first you will relax the muscles in your toes. - You feel heavy. - Let them go. At the same time, the robot tells the child to think of happy pictures to relax more easily (Storch et al., 2015). Simultaneously with the relaxation instructions, the robot's eyes light up in a light blue color, which relaxes the child even more. In addition, the hands are shaken up and down slowly at the best possible relaxation.

\section{Second Axis: Communication skills}

\section{Introduction}

Since it is common for children with autism to feel uncomfortable when new stimuli are introduced, it is usually recommended to give the child some space to become familiar with the robot. In this way it is less possible for the child to feel anxious or threatened (Severson et al., 2008). The primary parent of the child can be present in the room where the intervention is carried out, only to support the child if needed or to respond to verbal initiations that are addressed to them. It is noted that the parent shouldn't begin interacting with the child if it is not necessary during the intervention.

All activities described below aim towards enhancing the communication skills of children with ASD as part of their social skills. It is important to provide rewards that are enjoyable (like sensory rewards) after the successful completion of each activity, in order to engage the child more and elicit positive behaviors (Artoni et al., 2018). When the interventionist and the parent feel that the child is ready to engage, the robot-child interaction can begin.

\section{Getting to know the robot (introductory activity)}

The interventionist begins to explain what the robot is and describes it as an animal toy/friend. They ask the child if they like animals and continue to interact with them verbally. The interventionist must respond to the child's questions and encourage free play and verbal interaction during this activity.

When the child begins to interact freely with the robot, it can wave its hands, flash its eyes and say "Hello! I am here to play with you!" and "What's your name?". Only after the child responds the robot can introduce itself. At this time, the interventionist writes down the exact time that spoken words and phrases are pronounced by the child, to measure the frequency of verbal interactions. Verbal communication is divided into three categories: speech that is addressed towards the robot and speech that is addressed towards the interventionist and/or the parent. During this phase, non-verbal communication is also being measured, such as touching, petting, hugging, and kissing the robotic animal. 


\section{Naming Objects}

In this activity, the robot is assisting the child in order to name the objects that are shown on the robot's digital screen. There are three categories of objects (animals, colors, and shapes) and one object of each category is presented each time. During this activity, the robot does not act autonomously, but instead it is controlled by the interventionist using the "Wizard of Oz" ("WOz") technique, which enables them to determine and alter the robot's actions without the child being aware of that fact. When using "WOz" to operate a robotic system, the child that is attending intervention usually believes that the robot is acting autonomously and that it directly responds to its actions (Kim et al., 2012; Scassellati et al., 2012).

The first task is about naming the animals that are shown on the robot's screen. In the beginning, each animal is presented and named by the robot and the child must pay attention to remember the names of the animals that it is not already familiar with (e.g.: cat, dog, fish, bird, etc.). The robot says "Now, I'm going to show you some animals and I'm going to say their names. Are you ready?". When the child gives a positive response, the presentation begins. Next, the robot says "Now, I'm going to show you an animal and you will tell me its name! Let's go!'. For every animal that is presented, its name must be pronounced in order to continue to the next. If there is no response after 20 seconds, the interventionist continues with the next animal card.

When animal cards are presented, if the guess is right, the robot praises the child as a reward. If the guess is wrong, the robot says "Let's try again!" and one more chance is given. The robot remains idle only if the participant doesn't react. This rewarding system is based on the ABA method principles, where a child that is exhibiting a desirable behavior is being rewarded accordingly (Hamzah et al., 2014).

The second and the third task are following the same process that was described for the first task. The only change is in the objects that are displayed, which are colors (second task) and shapes (third task). In the second task, the colors are first presented to the child, and then it is asked to name each one after the robot displays a digital card with a colored balloon (e.g.: a red balloon, green balloon, blue balloon, etc.). The third task has the highest degree of difficulty, as shapes are concepts more abstract than colors and animals (which are animate). After each of these two tasks is complete, the child is rewarded just like in the first task, and the final reward is followed by the robot saying "Goodbye! I had a great time playing with you!" and waving its hand.

\section{Spontaneous request}

This activity aims at promoting spontaneous requesting for children with ASD using a robot. A robot can be an effective mediator for spontaneous speech and oral requests, thus promoting further engagement in educational activities (Desideri et al., 2017). Requests at this stage should be simple, easily comprehensible, and compatible with the child's interests. At this phase, requests are corresponding to storytelling, music playing, lights flashing, and dancing.

First, the interventionist must show case the four possible choices that the child has if it expresses a command. For example, the interventionist can say "lights!" and the child can see the robot's eyes flashing and flickering. This can be repeated several times and all commands can be given by them (e.g.: "lights!", "music!", "story!", "dance!”). The goal of this step is to catch the child's attention and to provide a general idea about this cause-and-effect process. The robot's action is in fact a type of sensory reward for the child, which has been also demonstrated in other studies (Duquette et al., 2008; Robins et al., 2005; Ferrari et al., 2009). When the interventionist feels like the child is ready, the main part of this activity can begin.

The robot is controlled by the interventionist or by another person that works as an operator for the intervention using the WOz technique that was described above through a tablet device. The robotic platform should be pre-programmed to execute those four requests immediately after the operator gives the signal for it to start on their tablet, in order to avoid 
confusion (Desideri et al., 2017). In addition, it should be placed in front of the child to be easily observable and catch their attention. The child's requests have the following effects:

- "Music": the robot plays a song (can be the only one song for many "music" requests or it can be a selection of two or three songs)

- "Lights": the robot flashes its eyes (this action can be combined with sounds too)

- "Story": the robot narrates a short story

- "Dance": the robot plays a song and moves its hands, head, and eyes (eye movement can be in combination with lights flashing)

The interventionist can give hints and encouragement to the child whenever they feel like it is not doing requests and usually after 10-20 seconds of idleness. In order to consider the intervention successful, the child must use at least two out of four requests verbally. Interventionists can measure the child's frequency of requests and their engagement in order to evaluate the effects on social behavior and communication.

\section{Which animal is this?}

This activity aims to enhance the child's verbal communication through choosing and playing with their preferred toy with the help of the robotic partner. The activity starts with the child seated in front of the robot, and the robot saying "We'll play with toys now!" and waving its hands. In between the child and the robot, there is a plastic tray where all toys can be placed(alternatively, it can be a shallow box). Three little stuffed animals are placed in the tray, and the child is free to pick up whichever it likes the most. Then the robot asks "What animal is this?" and the child must respond. If the response is wrong, the robot can pronounce the name of the animal correctly. Then, the robot asks the child to make the sound the animal does (e.g.: "How does the dog sound like?") and the child must respond accordingly. Then, the robot produces the animal's sound as well and the child must pick the next stuffed toy after a hint is given.

This phase can be completed when the child picks up all three animals and communicates with the robot, or the educator/interventionist can add more stuffed animals to the tray. It is important to give minimal help to the child when playing with the robot at this phase (Wood et al., 2018). This activity can be tailored according to the child's capabilities and knowledge of animal names and sounds. A successful interaction is involving verbal communication with the robot and potentially with the interventionist. Also, successful interactions can involve wrong answers about the animals' names and sounds. After each successful interaction, the child is rewarded in the same way as it was described in the preceding activities.

\section{Third Axis: Social skills}

\section{Familiarization phase}

Before the activities for the development of the child's social skills begin, the child must familiarize themselves with the robot. The child enters the room where the robot is located and is given time to explore the robot (Pennazio, 2017). Initially, the robot remains silent for 3 minutes only blinking its eyes and looking right and left whilst waiting for the child to get closer. After that time, if the child will not approach, the robot greets them (Hello!) and asks their name (What's your name?). In this phase, the child can explore the robot and talk with it.

\section{Activities}

Each session starts with the robot greeting the child, followed by the activities, and ended with a farewell. The robot then moves away from the workplace and closes its eyes, to let the child know that the session is over. 


\section{Imitation games}

Imitation plays an important role in learning social skills and play and is essential for the acquisition of a multitude of skills and knowledge (Dautenhahn \& Billard, 2002; Ingersoll, 2008). At an early stage, children explore their social environment through imitation (Cabibihan et al., 2013), which later helps to create and maintain interactions with peers. Deficits of children with ASD in imitation can obstruct the development of peer play and the learning and development of the child in general. For that reason, this skill must be strengthened in children with ASD (Ingersoll, 2008).

Initially, the robot tells a story, which is related to the four basic emotions (anger, happiness, sadness, fear), to the child and then invites them to play an imitation game with it (Costa et al., 2018). The robot takes various expressions and asks the child to do the same (saying: Now it's your turn). If the child does not respond, the robot makes the same expression again and asks the child to repeat it.

The activity then focuses on full-body movements (Duquette et al., 2008), which include movements of both the upper (e.g., upper arms, back arms, middle arms) and lower body movements (legs open, right leg forward, left foot back). The robot also asks the child to perform facial movements such as touching the face, nose, cheeks, etc.

Afterward, mirror exercises to enhance body awareness and social skills are carried out. In the beginning, the robot performs exercises with the arms (e.g., circular movements) and asks the child to imitate its movements. Gradually it passes to other more complex ones. When the child succeeds, the robot asks them to make the movements as if they were looking at themselves through a mirror. For example, if the robot raises the right hand the child needs to raise the left. Gradually more parts of the body are added, such as the head and legs, and the time spent doing the activity increases.

Subsequently, a walking game involving tracing letters and shapes on the floor takes place (Srinivasan et al., 2015a). The robot shows the process. It goes to the first letter, points it, and reads it (e.g., /'eI/). Then the robot asks the child to do the same, a process that is repeated with the shapes and colors.

Each time the child achieves the intended goal, the robot provides them with verbal praise (e.g., Well done! You did it!). If the child does not succeed, the robot repeats the movement and asks them to try again (e.g., Try again!), a process that is repeated until the child responds successfully.

\section{Turn-taking games}

The ability to take turns plays an important role in social communication and requires interaction partners to understand when to start and stop their turns into social interactions (David et al., 2020). The difficulties that children with ASD present in turn-taking deprive them of the opportunity to acquire new interaction skills, which in turn works by aggravating the deficits of these children in this behavior (Daubert et al., 2015). For this reason, children need to be involved in turn-taking activities.

First, the child enters the room where the robot and a textile ball are placed. The robot explains to the child that it will kick the ball at them and then it will wait for the child to do the same, saying "Now it's your turn!" (Cabibihan et al., 2013). Then, they play a second game where they have to put the pieces alternately to make a puzzle. First, the child is instructed to put the piece in the correct order and as soon as they complete the process the robot tells them "Now it's my turn" and the child has to wait until the robot finishes the process for their turn to come again. If the child does succeed the robot provides them with verbal praise (e.g., Well done! You did it!). If the child does not wait for their turn the robot tells them to try again (e.g., Try again!) (David et al., 2020). 


\section{Social and emotional understanding games}

Children with ASD have difficulty with social-emotional understanding and expression (Bauminger, 2002). These deficits affect the quality of social interactions with their peers (Wieckowski \& White, 2020) and it is, therefore, important the treatment program of children with ASD focuses on teaching and familiarizing themselves with recognizing and expressing emotions. Research has shown that experimenting with facial expressions contributes to the development of children with ASD social skills (Hourcade et al., 2012).

Initially, the child sits at the table, where sticks depicting different emotional expressions are placed. The robot tells the child an emotion and they have to pick up the corresponding stick. Each time that the child picks up the right stick they are asked to look at the partner and repeat the word given. This is done to establish the level of the pupil's eye contact and improve the interaction with the robot.

The child is then presented with the tablet placed on the work desk and the robot asks them to match each facial expression with the corresponding emotion (Hourcade et al., 2012). Each time the child succeeds, the robot provides a verbal reward. The robot then tells the child an emotion (e.g., joy) and asks them to give the same expression to the character on the tablet (i.e., to make the virtual hero happy) (Finkelstein et al., 2009).

The activity ends with learning the circumstances in which each emotion is expressed (Schuller et al., 2014) and the robot helps the child to understand how to recognize them. For example, the robot tells the child "My mother scolded me and I feel sad", while at the same time it gets the corresponding expression on its face. In the end, the robot gives similar examples to the child and asks them to tell how they feel in every situation (e.g., Yesterday I went to the playground and I had a great time, what did I feel?).

\section{Social story for social conventions understanding}

Social stories are short stories that describe social situations and present the desired way of action in them (Gray \& Garand, 1993). They prepare children with ASD so that they can manage a condition that confuses them or makes it difficult for them to understand (Ozdemir, 2008). As children with ASD have difficulty understanding the perspectives of others and the ability to respond to social situations like the rest of their peers (Gray C., 2013) a social story was chosen to help children understand the correct way to conduct a conversation.

Initially, the pieces of the story about conducting a conversation are mixed up and placed on the table where the child is sitting. The robot tells the social story to the child. Then it shows each card and reads the sentence written on it. Then the robot asks the child to put the cards in the correct order (Gray \& Garand, 1993). To make sure that the child understands the social story, the robot asks comprehension questions (Ozdemir, 2010). Finally, two pictures are presented to the child to establish if they have grasped the right and the wrong way to conduct a conversation.

\section{Fourth Axis: Motor skills}

Although motor difficulties are not a core symptom and are not included among the diagnostic criteria for ASD, there is evidence that indicates the presence of a variety of gross and fine motor impairments in individuals in the autism spectrum (Fournier et al., 2010). These motor difficulties have been reported across wide age ranges and are related to in coordination during gross and fine motor activities, poor balance skills, clumsy gait patterns, and impairments in motor imitation, praxis, and interpersonal synchrony (Hobson \& Lee, 1999). 


\section{Mirroring System}

The mirroring coaching platform consists of the robot and a camera as a motion tracking system. The robotic mirroring system can be used to implement different exercises in a triadic interaction, between an adult, a child, and the robot. The participants are in a triangle. The camera is positioned above the robot and opposite the people. The aim is to create an interactive game with meaningful gestures and train social and motor skills in ASD children. The robot may represent an individual. The robot shows a movement (i.e., waving, greeting movement done with the left arm; dragging, reaching the topleft position and back with two arms; picking, reaching the top position and back with each arm sequentially; pointing, pointing to a top position with one arm) and it gives a signal to the adult to repeat it. Afterward, the robot starts processing the recorded data, and it mirrors the adult. If the adult or the child performed the movement correctly, the robot gives positive feedback (e.g., "Great", "Bravo") and its LEDs become green. If the adult or the child does not perform the movement within the predetermined time, the LEDs of the robot turn red (Santos et al., 2021).

In the adult-master protocol, the adult is the master. They demonstrate the movement and ask the robot and the child to replicate it. The robot does not give any feedback at this phase. The theme can be sports (e.g., basket, bowling, swimming, tennis, and skiing). Each sport is associated with a representative movement (i.e., basket, throwing up a ball; bowling, throwing a ball forward with one arm; swimming, breaststroke movements; tennis, hitting a ball laterally; skiing, sliding the arms), and the adult is allowed to repeat it several times to show to the robot (Santos et al., 2021).

\section{Movement-based robotic activities}

These activities promote gross motor skills including balance, bilateral coordination, imitation, interpersonal synchrony, and mutual dexterity during joint action games. Strategies such as repetition, graded prompting, ensuring structure and consistency in the environment and the individuals can be involved in the training, and the use of pictures to facilitate transitions can be incorporated too. The children are engaged in training activities within a triadic context involving a child, a robot, and an adult model (Srinivasan et al., 2015b).

The robot is the instructor and a human trainer controls the robot using a computer. The adult model acts as a friend and a visual model for the child and can assist in the session if it is necessary. The group participates in a variety of dual and multi limb imitation and synchrony-based whole-body movement games. In each session, children practice the following movement-based games: greeting the trainer, the robot, and the model, warm-up game including whole-body stretches, action game involving upper and lower body synchrony games with the robot and the model, drumming game involving the practice of simple and complex drumming patterns with the robot and the model, and walking game involving tracing letters and shapes on the floor while following the robot. Social communication skills are promoted through this activity such as eye contact, turn-taking, greeting, farewell, responding to questions, commenting, asking for help, and use of gestures. Gross motor skills including balance, bilateral coordination, imitation, interpersonal synchrony, and manual dexterity during joint action games are promoted too.

\section{Ask for the animals}

During this game, the children learn that the robot has a different aspect of sight than their own. Moreover, it allows the children to explore what will happen if an object is moved from the robot's field of view or into the robot's field of view. The robot watches several animal toys that have been placed in various places in the classroom. The robot is not programmed to move or to look around, therefore the child has to put the objects into the robot's field of view. In addition, next to the robot there is a screen that shows what the robot can see. The robot can ask the child to show it particular animals, and the child has to find the appropriate animal toy and show it to the robot in an appropriate manner (i.e., put it in the robot's field of view or 
front of its face and at an appropriate distance from the eyes and/or face). In that case, the robot rewards the child (e.g., the robot makes the sound of the animal). At a second stage, the child is encouraged to play the game without the use of the screen. This is very important because in everyday life the children cannot see what other people or peers can see through a screen.

\section{Stories}

Praxis skills are associated with social impairments and imitation of gestures, which requires the production of coordinated movements. Attention is of great importance in gestural production. Children with ASD face attention impairments, which may prevent them from producing gestures. In this activity, gestures that are commonly used in everyday life are taught to the children. A robot that can produce a range of gestures is appropriate.

In the beginning, the researcher greets the participant and then gives the instruction. In case the participant does not understand them, the researcher repeats the instructions. Otherwise, the researcher narrates the whole story. Then, the researcher repeats each sentence and asks the participant to demonstrate the corresponding gesture. The participant is given about 10s to respond. The researcher judges the accuracy of the gesture and either continues with the story or gives feedback if it is necessary. Afterward, the robot narrates a set of different stories and gestures at the same time (So et al., 2018). Each time the participant is asked to imitate the gesture. A possible story may be: "Last week a friend of mine visited me at my home and he was hungry. He wanted to have dinner out. I asked him where he would like to go for dinner. He suggested eating steak. I said "awesome". The story can contain five sentences and two to three different gestures. The story is told by a speaker and sound effects can be used to make the recordings sound like the speech produced by a robot. The recording can be imported to the robot. In the above story, the robot narrates and gestures: "Last week a friend of mine visited me at my home and he was hungry (one arm bends on the belly up and down)" or "I asked him where (two arms open wide with palms facing up) he would like to go for dinner". A small reward (e.g., a snack or access to toys) can be offered at the end.

\section{Final Considerations}

The aim of this article was to provide contextual information about a panda-robot especially designed for children with ASD. Initially, its physical appearance is described and information about its characteristics is given. Then an intervention structured in four axes is presented. These four axes include activities that aim towards the development of social, communication, and motor skills and also focus on the implementation of relief and relaxation techniques for children with ASD. The selection of these axes was made after the fundamental deficits of children with ASD were taken into consideration and aimed towards strengthening the areas in which they lag behind. In the near future, it would be beneficial to investigate the effectiveness of the program to a large sample of participants and the data should be collected in laboratory conditions in order to check the reliability of the results. Future research could also implement the program in different contexts, such as schools, special treatment centers for children with ASD, and other settings. This will allow the generalization of results and the collection of more reliable data.

\section{References}

Artoni, S., Bastiani, L., Buzzi, M. C., Buzzi, M., Curzio, O., Pelagatti, S., \& Senette, C. (2018). Technology-enhanced ABA intervention in children with autism: a pilot study. Universal Access in the Information Society, 17(1), 191-210. https://doi.org/10.1007/s10209-017-0536-x

Bauminger, N. (2002). The facilitation of social-emotional understanding and social interaction in high-functioning children with autism: Intervention outcomes. Journal of autism and developmental disorders, 32(4), 283-298. https://doi.org/10.1023/a:1016378718278

Cabibihan, J. J., Javed, H., Ang, M., \& Aljunied, S. M. (2013). Why robots? A survey on the roles and benefits of social robots in the therapy of children with autism. International journal of social robotics, 5(4), 593-618.https://doi.org/10.1007/s12369-013-0202-2 
Costa, A. P., Charpiot, L., Lera, F. R., Ziafati, P., Nazarikhorram, A., Van Der Torre, L., \& Steffgen, G. (2018, August). More attention and less repetitive and stereotyped behaviors using a robot with children with autism. In 27th IEEE International Symposium on Robot and Human Interactive Communication (ROMAN) (pp. 534-539). https://doi.org/10.1109/ROMAN.2018.8525747

Daubert, A., Hornstein, S., \& Tincani, M. (2015). Effects of a modified power card strategy on turn taking and social commenting of children with autism spectrum disorder playing board games. Journal of Developmental and Physical Disabilities, 27(1), 93-110.https://doi.org/10.1007/s10882-014-9403-3

Dautenhahn, K., \& Billard, A. (2002). Games children with autism can play with Robota, a humanoid robotic doll. In: S. Keates, P. M. Langdon, P.J. Clarkson, \&P. Robinson (Eds.), Universal Access and Assistive Technology (pp.179- 190). Springer.

David, D. O., Costescu, C. A., Matu, S., Szentagotai, A., \&Dobrean, A. (2020). Effects of a robot-enhanced intervention for children with ASD on teaching turn-taking skills. Journal of Educational Computing Research, 58(1), 29-62. https://doi.org/10.1177/0735633119830344

Desideri, L., Negrini, M., Cutrone, M. C., Rouame, A., Malavasi, M., Hoogerwerf, E. J., Bonifacci, P., \& Di Sarro, R. (2017). Exploring the use of a humanoid robot to engage children with autism spectrum disorder (ASD). In Harnessing the Power of Technology to Improve Lives (pp. 501-509). IOS Press.

Duquette, A., Michaud, F., \& Mercier, H. (2008). Exploring the use of a mobile robot as an imitation agent with children with low-functioning autism. Autonomous Robots, 24(2), 147-157.https://doi.org/10.1007/s10514-007-9056-5

Ferrari, E., Robins, B., \& Dautenhahn, K. (2009, September). Therapeutic and educational objectives in robot assisted play for children with autism. In $R O$ MAN 2009-The 18th IEEE international symposium on robot and human interactive communication (pp. 108-114). IEEE.

Filiou, A.E. (2021). Mental disorders in children and adolescents with autism Application of Cognitive and Behavioural Therapy and other early interventions in Syriopoulou- Delli, C., Folostina R. (2021) Interventions for Improving Adaptive Behaviors in Children With Autism Spectrum Disorders. IGI Global.

Finkelstein, S. L., Nickel, A., Harrison, L., Suma, E. A., \& Barnes, T. (2009, March). cMotion: A new game design to teach emotion recognition and programming logic to children using virtual humans. In 2009 IEEE Virtual Reality Conference (pp. 249-250).https://doi.org/10.1109/VR.2009.4811039

Fournier, K. A., Naik, S. K., Hass, C. J., Lodha, N., \& Cauraugh, J. H. (2010). Motor coordination in Autism Spectrum Disorders: A synthesis and metaanalysis. Journal of Autism and Developmental Disorders, 40(10), 1227-1240. DOI: 10.1007/s10803-010-0981-3

Gray, C. (2013). Social Stories. In N. Grove (Eds), Using Storytelling to Support Children and Adults with Special Needs (pp. 95-101). Routeledge.

Gray, C. A., \& Garand, J. D. (1993). Social stories: Improving responses of students with autism with accurate social information. Focus on autistic behavior, 8(1), 1-10.https://doi.org/10.1177/108835769300800101

Hamzah, M. S. J., Shamsuddin, S., Miskam, M. A., Yussof, H., \& Hashim, K. S. (2014). Development of interaction scenarios based on pre-school curriculum in robotic intervention for children with autism. Procedia Computer Science, 42, 214-21.

Hobson, R. P., \& Lee, A. (1999). Imitation and identification in autism. Journal of Child Psychology and Psychiatry, 40(4), 649-59. https://doi.org/10.1111/1469-7610.00481

Hourcade, J. P., Bullock-Rest, N. E., \& Hansen, T. E. (2012). Multitouch tablet applications and activities to enhance the social skills of children with autism spectrum disorders. Personal and ubiquitous computing, 16(2), 157-168. https://doi.org/10.1007/s00779-011-0383-3

Ingersoll, B. (2008). The social role of imitation in autism: Implications for the treatment of imitation deficits. Infants \& Young Children, 21(2), 107119.https://doi.org/10.1097/01.IYC.0000314482.24087.14

Kim, E., Paul, R., Shic, F., \& Scassellati, B. (2012). Bridging the Research Gap: Making HRI Useful to Individuals with Autism. Journal of Human-Robot Interaction, 1(1), 26-54.https://doi.org/10.5898/jhri.1.1.kim

Kozima, H., Michalowski, M. P., \& Nakagawa, C. (2009). Keepon. A Playful Robot for Research, Therapy, and Entertainment. International Journal of Social Robotics, 1(1), 3-18.http://dx.doi.org/10.1007/s12369-008-0009-8

Kumazaki, H., Muramatsu, T., Yoshikawa, Y., Matsumoto, Y., Ishiguro, H., Kikuchi, M., Sumiyoshi, T., \& Mimura, M. (2020). Optimal robot for intervention for individuals with autism spectrum disorders. Psychiatry and Clinical Neurosciences, 74(11), 581-6.https://doi.org/10.1111/pcn.13132

Landauer, T. K. (1986).Psychology as a mother of invention. ACM SIGCHI Bulletin, 18(4), 333-5. https://doi.org/10.1145/1165387.275653

Marino, F., Chilà, P., Trusso Sfrazzetto, S., Carrozza, C., Crimi, I., Failla, C., Busà, M., Bernava, G., Tartarisco, G., Vagni, D., Ruta, L.,\&Pioggia, G. (2020). Outcomes of a Robot-Assisted Social-Emotional Understanding Intervention for Young Children with Autism Spectrum Disorders. Journal of Autism and Developmental Disorders,50, 1973-1987.https://doi.org/10.1007/s10803-019-03953-x.

Omair, A. (2015). Selecting the appropriate study design for your research: Descriptive study designs. Journal of Health Specialties, 3(3), 153.

Ozdemir, S. (2008). The effectiveness of social stories on decreasing disruptive behaviors of children with autism: Three case studies. Journal of Autism and Developmental Disorders, 38(9), 1689-96. https://doi.org/10.1007/s10803-008-0551-0

Ozdemir, S. (2010). Social stories: an intervention technique for children with Autism. Procedia-Social and Behavioral Sciences, 5, 1827-30. https://doi.org/10.1016/j.sbspro.2010.07.372

Peca, A., Simut, R., Pintea, S., Costescu, C., \& Vanderborght, B. (2014). How do typically developing children and children with autism perceive different social robots? Computers in Human Behavior, 41, 268-77. https://doi.org/10.1016/j.chb.2014.09.035

Pennazio, V. (2017). Social robotics to help children with autism in their interactions through imitation. Research on Education and Media, 9(1), 1016.https://doi.org/10.1515/rem-2017-0003 
Rezigalla A. A. (2020). Observational Study Designs: Synopsis for Selecting an Appropriate Study Design. Cureus, $12(1)$, e6692. https://doi.org/10.7759/cureus.6692

Robins, B., Dautenhahn, K., Boekhorst, R. T.,\& Billard, A. (2005). Robotic assistants in therapy and education of children with autism: can a small humanoid robot help encourage social interaction skills?. Universal access in the information society, 4(2), 105-20.

Robins, B., Ferrari, E., Dautenhahn, K., Kronreif, G., Prazak-Aram, B., Gelderblom, G. J., Tanja, B., Caprino, F., Laudanna, E., \& Marti, P. (2010). Humancentred design methods: Developing scenarios for robot assisted play informed by user panels and field trials. International Journal of Human-Computer Studies, 68(12), 873-98. https://doi.org/10.1075/is.13.2.03rob

Saadatzi, M. N., Pennington, R. C., Welch, K. C., \& Graham, J. H. (2018). Small-group technology-assisted instruction: Virtual teacher and robot peer for individuals with autism spectrum disorder. Journal of Autism and Developmental Disorders, 48(11), 3816-30.

Santos, L., Geminiani, A., Schyllo, P., Olivieri, I., Santos-Victor, J., \& Pedrocchi, A. (2021). Design of a Robotic Coach for Motor, Social and Cognitive Skills Training Toward Applications With ASD Children. IEEE Engineering in Medicine and Biology Society, 99(1). DOI: 10.1109/TNSRE.2021.3091320

Sartorato, F., Przybylowski, L., \& Sarko, D. K. (2017). Improving therapeutic outcomes in autism spectrum disorders: Enhancing social communication and sensory processing through the use of interactive robots. Journal of Psychiatric Research, 9, 1-11. https://doi.org/10.1016/j.jpsychires.2017.02.004.

Scassellati, B., Admoni, H., \& Matarić, M. (2012). Robots for use in autism research. Annual review of biomedical engineering, 14, 275-294.

Schuller, B., Marchi, E., Baron-Cohen, S., O'Reilly, H., Pigat, D., Robinson, P., \& Daves, I. (2014, March). The state of play of ASC-Inclusion: an integrated Internet-based environment for social inclusion of children with autism spectrum conditions. In Computing Research Repository (CoRR).https://arxiv.org/abs/1403.5912

Sharma, S. R., Gonda, X., \& Tarazi, F. I. (2018). Autism spectrum disorder: Classification, diagnosis and therapy. Pharmacology and Therapeutics. https://doi.org/10.1016/j.pharmthera.2018.05.007.

So, W. C., Wong, M. K. Y., Lam, W. Y., Cheng, C. H., Yang, J. H., Huang, Y., Ng, P., Wong, W. L., Ho, C. L., Yeung, K. L., \& Lee, C. C. (2018). Robotbased intervention may reduce delay in the production of intransitive gestures in Chinese-speaking preschoolers with autism spectrum disorder. Molecular Autism, 9(34). DOI: 10.1186/s13229-018-0217-5

Spain, D., Sin, J., Chalder, T., Murphy, D., \& Happe, F. (2015). Cognitive behaviour therapy for adults with autism spectrum disorders and psychiatric comorbidity: A review. Research in Autism Spectrum Disorders, 9, 151-162. https://doi.org/10.1016/j.rasd.2014.10.019.

Sprung, M., Münch, H. M., Harris, P. L., Ebesutani, C., \& Hofmann, S. G. (2015). Children's emotion understanding: A meta-analysis of training studies. Developmental Review, 37, 41-65. https://doi. org/10.1016/j.dr.2015.05.001.

Srinivasan, S. M., Kaur, M., Park, I. K., Gifford, T. D., Marsh, K. L., \& Bhat, A. N. (2015a). The Effects of Rhythm and Robotic Interventions on the Imitation/Praxis, Interpersonal Synchrony, and Motor Performance of Children with Autism Spectrum Disorder (ASD): A Pilot Randomized Controlled Trial. Autism Research and Treatment, 1, 1-18. DOI: 10.1155/2015/736516.

Srinivasan, S. M., Park, I. K., Neelly, L. B., \& Bhat, A. N. (2015b). A comparison of the effects of rhythm and robotic interventions on repetitive behaviors and affective states of children with Autism Spectrum Disorder (ASD). Research in autism spectrum disorders, 18, 51-63. https://doi.org/10.1016/j.rasd.2015.07.004

Stanton, C. M., Kahn, P. H., Severson, R. L., Ruckert, J. H., \& Gill, B. T. (2008, March). Robotic animals might aid in the social development of children with autism. Proceedings of the 3rd ACM/IEEE International Conference on Human-Robot Interaction (HRI) (pp. 271-278). ACM Digital Library. https://doi.org/10.1145/1349822.1349858

Storch, E.A., Lewin, A.B., Collier, A.B., Arnold, E., De Nadai, A.S., Dane, B.F. et al. (2015). Arandomized controlled trial of cognitive-behavioral therapy versus treatment as usual for adolescents with autism spectrum disorders and comorbid anxiety. Depress Anxiety, 32, 174-81. https://doi.org/10.1002/da.22332.

Syriopoulou Delli, C., Gkiolnta, E. (2021). Effectiveness of different types of Augmentative and Alternative Communication (AAC) in improving communication skills and in enhancing the vocabulary of children with ASD: A review Review Journal of Autism and Developmental Disorders DOI $10.1007 / \mathrm{s} 40489-021-00269-4$

Syriopoulou- Delli, C., Sarri, K. (2021). Video-Based Instruction in enhancing Functional Living Skills of adolescents and young adults with Autism Spectrum Disorder: A review. DOI: 10.1080/20473869.2021.1900504. International Journal of Developmental Disabilities. https://www.tandfonline.com/eprint/DVRTIGR33AZVGGI2HASW/full?target=10.1080/20473869.2021.1900504

Syriopoulou- Delli, C., Gkiolnta, E. (2021). Robotics and Inclusion of Students with Disabilities in Special Education. Journal Research, Society and Development 10(9): DOI: 10.33448/rsd-v10i9.18238.

Syriopoulou- Delli, C., Zygopoulou, M (2021). Robot Enhanced Interventions and Repetitive and Stereotyped Behaviors in Children with Autism Spectrum Disorder. A Scoping Review. Journal Research, Society, Development 10(11) DOI: http://dx.doi.org/10.33448/rsd-v10i11.20269.

Vanderborght, B., Simut, R., Saldien, J., Pop, C., Rusu, A. S., Pintea, S., Lefeber, D., \& David, D. O. (2012). Using the social robot probo as a social story telling agent for children with ASD. Interaction Studies, 13(3), 348-72. https://doi.org/10.1075/is.13.3.02van

Wieckowski, A. T., \& White, S. W. (2020). Attention modification to attenuate facial emotion recognition deficits in children with autism: A pilot study. Journal of autism and developmental disorders, 50(1), 30-41. https://doi.org/10.1007/s10803-019-04223-6

Wilson, J., \& Rosenberg, D. (1988). Rapid prototyping for user interface design. In Handbook of human-computer interaction (pp. 859-75). North-Holland. 
Research, Society and Development, v. 10, n. 16, e218101623763, 2021

(CC BY 4.0) | ISSN 2525-3409 | DOI: http://dx.doi.org/10.33448/rsd-v10i16.23763

Wood, J.J., Kendall, P.C., Wood, K.S., Kerns, C.M., Seltzer,M., Small,B.J., Lewin, A. B.,\&Storch, E.A. (2020). Cognitive Behavioral Treatments for Anxiety in Children with Autism Spectrum Disorder: A Randomized Clinical Trial. JAMA Psychiatry, 5, 474-483. https://doi.org/ 10.1001/jamapsychiatry.2019.4160.

Wood, L. J., Robins, B., Lakatos, G., Syrdal, D. S., Zaraki, A., \& Dautenhahn, K. (2018, July). Piloting scenarios for children with autism to learn about visual perspective taking. In Annual Conference Towards Autonomous Robotic Systems (pp. 260-270). Springer, Cham.

Yun, S.S., Choi, J., Park, S.K., Bong, G.Y., \& Yoo, H. (2017). Social skills training for children with autism spectrum disorder using a robotic behavioral intervention system. Autism Research, 10(7), 1306-1323. https://doi.org/10.1002/aur.1778. 